\title{
Penerapan Media Lectora Inspire dan Aplikasi Wingeom untuk Meningkatkan Hasil Belajar Mahasiswa pada Materi Geometri
}

\author{
Rizka Rizqi Robby ${ }^{(1)}$ Ardhi Sanwidi(2) \\ ${ }^{1,2}$ Dosen Program Studi Matematika \\ Universitas Nahdlatul Ulama Blitar, Indonesia
}

Email: 1'rizka.ertiga@gmail.com ,2ardhisanwidi@unublitar.ac.id

\section{Tersedia Online di}

http://www.jurnal.unublitar.ac.id/

index.php/briliant

\begin{tabular}{l}
\hline Sejarah Artikel \\
\hline Diterima pada 27 Agustus 2019 \\
Disetujui pada 29 Agustus 2019 \\
Dipublikasikan pada 31 Agustus \\
2019 Hal. 394-400
\end{tabular}

Kata Kunci:

Media lectora inspire, aplikasi wigeom, geometri bidang 3 dimensi

DOI:

http://dx.doi.org/10.28926/briliant .v3i4.358

\begin{abstract}
Abstrak: Penelitian ini merupakan penelitian tindakan kelas yang dilakukan di UNU Blitar pada mahasiswa matematika tahun ajaran 2018/2019 untuk meningkatkan hasil belajar materi geometri bidang 3 dimensi. Penelitian dilaksanakan dalam dua siklus, setiap siklus meliputi tahapan perencanaan, tindakan, observasi dan refleksi. Hasil belajar mahasiswa meningkat dari rata-rata kelas 62,3 menjadi 76,9 , sehingga memenuhi kriteria minimal baik. Aktivitas mahasiswa meningkat dari $42 \%$ menjadi $80 \%$. Respon mahasiswa terhadap pembelajaran sangat baik, terbukti presentasi naik dari $40 \%$ menjadi $80 \%$. Pembelajaran langsung dengan menggunakan media lectora inspire dan aplikasi wingeom dapat meningkatkan hasil belajar mahasiswa mahasiswa dalam matakuliah geometri bidang 3 dimensi.
\end{abstract}

\section{PENDAHULUAN}

Salah satu cabang dari ilmu matematika yang sangat penting adalah geometri. Van de well (2016) mengungkapkan bahwa ada 5 alasan mengapa geometri itu sangat penting untuk dipelajari di matematika, (1) geometri membantu manusia memiliki imajinasi yang utuh tentang dunianya, (2) eksplorasi geometri dapat membantu mengembangkan keterampilan spasial, (3) geometri memerankan peranan utama dalam mempelajari ilmu matematika lainnya, (4) geometri digunakan oleh banyak orang dalam kehidupan sehari-hari, dan (5) geometri penuh teka-teki dan menyenangkan untuk dipelajari.

Observasi yang dilakukan di Universitas Nahdlatul Ulama Blitar, menemukan bahwa mahasiswa melakukan banyak kesalahan ketika menyelesaikan soal-soal mengenai bangun ruang, saat diwawancarai, mahasiswa mengungkapkan bahwa penyebab kesalahan tersebut adalah masih kurang mengerti dengan materi 3 dimensi, terutama dalam susunan jaring-jaring bangun ruang, diagonal ruang dan perhitungannya. Selain itu, dari hasil nilai ujian akhir semester yang dilakukan,hanya 5 dari 34 mahasiswa mendapatkan nilai 70 dan 29 mahasiswa mendapat nilai kurang dari 65. Nilai rata-rata 34 mahasiswa sebesar 61,15. Hasil dari nilai rata-rata tersebut dianggap kurang memenuhi kriteria ketuntasan, dimana telah ditentukan nilai kriteria minimal $\mathrm{B}$ harus mendapatkan nilai 70. 
Beberapa penelitian (Softnider dkk, 2013; Pratiwi \& Septia, 2016) menyebutkan bahwa kesalahan konsep dasar geometri yang disajikan mahasiswa, seperti menyebut bangun datar atau bangun ruang, klasifikasi masing-masing bangun tersebut sering salah, tidak jelasnya perbedaan sifat-sifat masing-masing bangun tersebut dan lain-lainnya. Studi pendahuluan yang telah dilakukan, terlihat adanya kelemahan dalam proses pembelajara, dimana masih mengunakan pembelajaran konvensioal. Adanya kelemahan dalam pembelajaran langsung yang bersifat konvensional, perlu ada suatu upaya untuk mengatasi hal tersebut. Salah satunya adalah menggunakan model, metode dan media pembelajaran secara tepat dalam pembelajaran, sehingga peserta didik termotivasi dengan adanya pembelajaran (Ariani \& Hariyanto, 2010) sehingga nilai mahasiswa bisa memenuhi kriteria baik.

Menggunakan media pembelajaran yang interaktif dan menarik membuat mahasiswa dan dosen akan terlibat aktif dalam pembelajaran (Sanwidi \& Swastika, 2019). Media merupakan perantara atau saluran komunikasi untuk menyampaikan pesan atau pendapat atau informasi kepada penerima pesan (Kustandi \& Sucipto, 2011; Kemp \& Dayton, 1985). Penggunaan media dalam pembelejaran memungkingkan mahasiswa untuk mendapatkan pemahaman dan keyakinan yang lebih baik sebelum mencoba suatu bukti formal atau pembuktian serta dapat meningkatkan hasil belajar mahasiswa. Kemp dan Dayton (1985) menyatakan bahwa kontribusi media pembelajaran dalam menyampaikan pesan pembelajaran lebih terstandarisasi, lebih menarik, lebih interaktif, waktu belajar dapat dipersingkat, kualitas pembelajaran dapat ditingkatkan, proses pembelajaran dapat berlangsung tanpa batas waktu, siswa berperilaku dan dosen memainkan peran positif terhadap pembelajaran.

Salah satu media pembelajaran interaktif yang dapat digunakan untuk membuat pembelajaran lebih menarik adalah Lectora Inspire. Lectora Inspire merupakan software pengembangan belajar elektronik (e-learning) yang relatif mudah digunakan atau diterapkan. Diantara beberapa keunggulan Lectore yang dikemukakakan Mas'ud (2012), penggunaan Lectora pada mata kuliah Geometri dapat didesain dan dibuat beberapa slide, menampilkan video animasi, serta gambar - gambar yang berhubungan dengan teori - teori pada geometri agar mahasiswa lebih memperhatikan apa yang disampikan. Penggunaan media lecotra inspire akan meningkatkan aktivitas belajar dan hasil belajar (Sanwidi \& Swastika, 2019). Selain media Lectora Inspire, salah satu program aplikasi komputer yang mendukung pembelajaran adalah program Wingeom. Program Wingeom dapat membantu memvisualisasikan suatu konsep geometri dengan jelas sehingga mahasiswa akan lebih mudah memahami konsep-konsep geometri. Dengan program Wingeom, mahasiswa dapat mengeksplorasi, mengamati, melakukan animasi bangun-bangun dan tampilan materi geometri (Pratiwi \& Septia, 2016).

Berdasarkan permasalahan di atas maka peneliti melakukan penelitian terkait penelitian tindakan kelas dengan menerapkan model pembelajaran langsung dengan berbantuan aplikasi wingeom dan sofrware lectora inspire dalam upaya memperbaiki pembelajaran dan meningkatkan hasil belajar mahasiswa pada materi geometri 3 dimensi. Peneliti menerapkan atau mengimplementasikan hasil dari pengembangan bahan ajar dengan bantuan media software lectra inspire yang telah dilakukan oleh Sanwidi \& Swastika (2018) dan modul Aplikasi Komputer 
Dengan Program Wingeom pada Materi Geometri yang telah dikembangkan oleh Pratiwi dan Septia (2016) dengan beberapa modifikasi agar sesuai dengan situasi dan kondisi dilapangan serta kemampuan mahasiswa.

\section{METODE}

Jenis penelitian ini adalah penelitian tindakan di mana investigasi atau studi sistematis dan terencana dilakukan oleh peneliti untuk meningkatkan pembelajaran di kelas dengan membuat perbaikan atau perubahan dan mempelajari konsekuensinya (Sunardi dkk, 2001). Penelitian ini dimulai dengan implementasi tindakan yang terdiri dari perencanaan, implementasi, pengamatan, refleksi terakhir. Penelitian ini dilakukan di kelas matakuliah Geometri mahasiswa matematika Universitas Nahdlatul Ulama Blitar, tahun ajaran 2018/2019 sejumlah 34 mahasiswa

Jika diketahui lokasi keberhasilan atau hambatan dari implementasi siklus I, peneliti menentukan desain untuk implementasi siklus II dan seterusnya, serta kegiatan pembelajaran dalam 1 siklus dilakukan dalam 3 pertemuan. Hasil dari siklus terakhir akan digunakan sebagai pedoman untuk melihat peningkatan hasil belajar siswa. Jika pada siklus kedua, hasil belajar siswa diperoleh lebih dari hasil belajar siswa pada siklus I, pembelajaran dihentikan sampai dua siklus saja. Instrumen penelitian yang digunakan adalah dalam bentuk tugas dan tes di setiap siklus. Selain itu, peneliti menggunakan software Lectora Inspire dan aplikasi wingeom yang membantu sebagai media pembelajaran pada materi Geometri untuk digunakan dalam pembelajaran. Catatan lapangan digunakan untuk menentukan kegiatan mahasiswa dan dosen selama pembelajaran. Dalam penelitian ini metode pengumpulan data yang digunakan adalah observasi, tes dan wawancara.

Analisis data yang digunakan dalam penelitian ini adalah analisis deskriptif kualitatif, yaitu: 1) tanggapan dosen dan mahasiswa terhadap Lectora Inspire dan aplikasi Wingeom melalui wawancara; 2)Kegiatan siswa selama proses pembelajaran; 3)Hasil belajar siswa setelah pembelajaran berlangsung. Rata-rata hasil belajar siswa diperoleh dari nilai tes pretest dan final. Data kualitatif adalah respon dari kegiatan dosen dan mahasiswa, dianalisis menggunakan metode yang mengacu pada Miles Huberman (Sugiyono, 2009), yaitu reduksi data, penyajian data, dan penarikan kesimpulan.

\section{HASIL}

Peneliti merupakan pengajar Geometri di Universitas Nahdlatul Ulama Blitar. Peneliti menilai pembelajaran sebelumnya belum berhasil dalam mengajar geometri bidang 3 dimensi dengan melihat hasil Ujian Akhir Semester mahasiswa yang mendapatkan nilai rata-rata 61 . Sehingga perlu untuk merefleksikan diri terhadap ketidakberhasilan tersebut. Beberapa faktor diantaranya disebabkan oleh penggunaan model pembelajaran yang belum melibatkan mahasiswa dalam keaktifan belajar dikelas yakni model pengajaran langsung. Selain itu, peneliti juga mengamati karena memang dari faktor kemampuan mahasiswa yang rendah. Pada tahun ajaran 2018/2019 di mata kuliah geometri, sebagai langkah awal dalam memperbaiki pembelajaran, Peneliti memilih model pembelajaran langsung dengan berbantuan media software lectora inspire dan aplikasi wingeom untuk diterapkan dan memberikan pretest terhadap mahasiswa. Hasil pretest dijadikan 
gambaran terhadap kemampuan mahasiswa. Berdasarkan hasil preetest tersebut maka diberikan tindakan untuk mendapatkan hasil belajar yang baik. Dibawah ini merupakan tabel hasil kegiatan pada siklus pertama dengan pembelajaran menggunakan aplikasi wingeom dan software lectora inspire.

Tabel 1. Data hasil opeservasi siklus pertama

\begin{tabular}{|l|c|c|c|}
\hline \multirow{2}{*}{\multicolumn{2}{|c|}{ Data observasi }} & \multicolumn{3}{|c|}{ Prosentase dan nilai siklus pertama } \\
\cline { 2 - 4 } & $\begin{array}{c}\text { Pertemuan } \\
1\end{array}$ & $\begin{array}{c}\text { Pertemuan } \\
2\end{array}$ & $\begin{array}{c}\text { Pertemuan } \\
3\end{array}$ \\
\hline Memperhatikan penjelasan dosen & $70 \%$ & $71 \%$ & $85 \%$ \\
\hline Kolaborasi dalam kegiatan kelompok & $57 \%$ & $60 \%$ & $62 \%$ \\
\hline Mempresentasikan hasil pekerjaan & $45 \%$ & $50 \%$ & $60 \%$ \\
\hline Mengeluarkan pendapat & $30 \%$ & $43 \%$ & $50 \%$ \\
\hline Rata-rata hasil nilai tes & 62,3 & 68 & 69,7 \\
\hline
\end{tabular}

Dari tabel 1 dapat dilihat bahwa mahasiswa kurang aktif dalam kegiatan mengutarakan pendapat atau hasil dari pekerjaannya sendiri ke depana kelas. Hal ini terlihat padda tabel diatas, bahwa prosentase tertinggi hanya 50\% mahasiswa saja yang mau mengutarakan pendapat, sedangkan yang lain hanya diam saja. Rata-rata nilai kelas dari pertemuan 1 sampai 3 terlihat meningkat, namun belum memenuhi kriteria minimal untuk memperoleh nilai B yaitu 70. Dari hasil pelaksanaan siklus pertama, peneliti merasa masih perlu meningkatkan keaktifan mahasiswa dan nilai mahasiswa untuk memperoleh nilai kriteria minimal. Untuk itu diadakan siklus kedua dengan sedikit perbaikan pada bahan ajar dan penggunaan media interaktif. Data hasil siklus kedua dapat dilihat pada tabel dibawah ini.

Tabel 2. Data hasil opeservasi siklus kedua

\begin{tabular}{|l|c|c|c|}
\hline \multirow{2}{*}{\multicolumn{1}{|c|}{ Data observasi }} & \multicolumn{3}{|c|}{ Prosentase dan nilai siklus kedua } \\
\cline { 2 - 4 } & $\begin{array}{c}\text { Pertemuan } \\
4\end{array}$ & $\begin{array}{c}\text { Pertemuan } \\
5\end{array}$ & $\begin{array}{c}\text { Pertemuan } \\
6\end{array}$ \\
\hline Memperhatikan penjelasan dosen & $84 \%$ & $90 \%$ & $95 \%$ \\
\hline Kolaborasi dalam kegiatan kelompok & $70 \%$ & $81 \%$ & $92 \%$ \\
\hline Mempresentasikan hasil pekerjaan & $65 \%$ & $73 \%$ & $80 \%$ \\
\hline Mengeluarkan pendapat & $60 \%$ & $75 \%$ & $79 \%$ \\
\hline Rata-rata hasil nilai tes & 71 & 73,7 & 76,9 \\
\hline
\end{tabular}

Tabel 2 memperlihatkan bahwa ada kenaikan siknifikan keaktifan mahasiswa dari pertemuan sebelumnya, serta peningkatan nilai yang signifikan dari pertemuan 4 sampai ke-6. Dari keseluruhan mahasiswa mendapatkan nilai minimal 71,6 dan tertinggi mencapai nilai 81 serta rata2 nilai kelas adalah 76,9. 


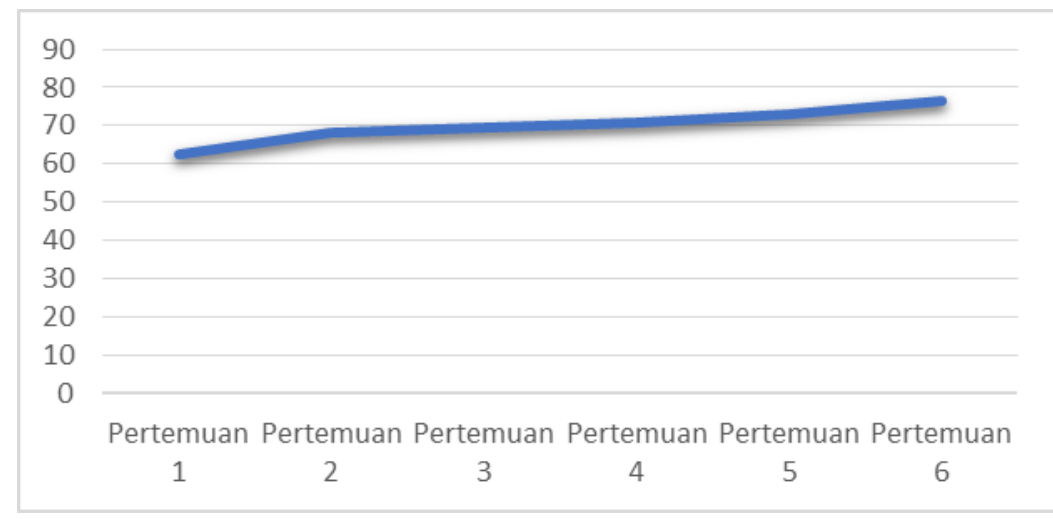

Gambar 1. Representasi peningkatan hasil belajar mahasiswa

Dapat dilihat bahwa seluruh mahasiswa sudah mencapai nilai kriteria minimal yaitu 70. Dari siklus ke-2, peneliti tidak lagi melakukan ke siklus ke-3, karena sudah ada kenaikan yang signifikan pada siklus ke-2 pertemuan ke-6, sehingga penelitian berhenti pada siklus ke-2 pertemuan ke-6.

Dari siklus satu dan siklus 2 terlihat peningkatan hasil belajar mahasiswa yang cukup signifikan dari 62,3 hingga pada pertemuan terakhir mencapai 76,6. Hal ini berarti penggunaan media pada model pembelajaran langsung sangat efektif untuk meningkatkan hasil belajar mahasiswa. Hasil peningkatan dapat dilihat di gambar 1.

\section{PEMBAHASAN}

Dari hasil penelitian yang telah dilakukan dapat dilihat bahwa penelitian tindakan kelas yang dilakukan dapat meningkatkan hasil belajar mahasiswa. Penggunaan media pembelajaran lectora inspire dan aplikasi wingeom yang digunakan dalam penelitian ini dapat meningkatkan hasil belajar mahasiswa dari pertemuan 1 sampai pertemuan ke-6. Peningkatan hasil belajar mahasiswa dapat dilihat pada gambar 1, dimana ada peningkatan signifikan rata-rata mahasiswa dan memenuhi kriteria minimal nilai B. Sejalan dengan penelitian dari pratiwi \& septia (2016) bahwa dengan menggunakan aplikasi wingeom dapat meningkatkan hasil belajar mahasiswa. Selain itu, dengan menggunakan aplikasi wingeom pada materi geometri bidang 3 dimensi dapat mempermudah mahasiswa mengabstrakai bidang 3 dimensi yang sulit divisualisasikan oleh mahasiswa.

Selain itu, dengan menggunakan software lectora inspire dapat meningkatkan keaktifan mahasiswa dimana pembelajaran jadi lebih menarik. Lectora inspire dapat meningkatkan keaktifan mahasiswa, hali ini terlihat pada tabel 1 dan tabel 2. Hal ini sejalan dengan penelitian yang dilakukan oleh Sanwidi \& Swastika (2019) bahwa dengan menggunakan software lectora inspire, pembelajaran langsung yang kurang menarik menjadi lebih menarik dan meningkatkan keantusiasan mahasiswa untuk belajar, terutama pada mata kuliah geometri yang biasanya dosen hanya menggambar dipapan yang dianggap kurang menarik.

Tabel 1 dan tabel 2 memperlihatkan bahwa mahasiswa lebih aktif dalam belajar geometri bidang 3 dimensi baik secara individu maupun secara kelompok. Dari pertemuan 1 sampai pertemuan ke-6 dapat terlihat bahwa terjadi peningkatan dalam memperhatikan penjelasan dosen dengan menggunakan software lectora 
dan aplikasi wingeom, kolaborasi dalam kegiatan kelompok ketika mengguanakan aplikasi wingeom meningkat sehingga dapat meningkatkan pemahaman mahasiswa tentang bidang 3 dimansi. Selain itu, dengan menggunakan aplikasi wingeom, keaktifan mahasiswa dalam mempresentasikan hasil pekerjaannya menjadi lebih meningkat, terlihat peningkatan yang terus menerus dari siklus satu maupun siklus 2 yang terlihat di tabel 1 dan tabel 2 .

\section{KESIMPULAN}

Penggunaan media lectora inspire dan aplikasi wingeom dapat meningkatkan hasil belajar mahasiswa pada materi geometri bidang 3 dimensi. Terlihat hasil nilai test rata2 mahasiswa meningkat dari 62,3 menjadi 76,9 . Selain meningkatkan hasil belajar mahasiswa, penggunaan media yang menarik juga dapat meningkatkan keaktifan mahasiswa dalam pembelajaran, terlihat dari hasil penelitian bahwa prosentase memperhatikan dosen ketika mengajar meningkat dari 70\% menjadi 95\%. Keaktifan dalam bekerja kelompok juga meningkat, dari prosentase $57 \%$ menjadi $92 \%$. Selain itu, mahasiswa menjadi lebih aktif dalam mengeluarkan pendapat maupun mempresentasikan hasil pekerjaan, terlihat peningkatan yang signifikan dari $45 \%$ dan $30 \%$ menjadi $80 \%$ dan $79 \%$.

\section{SARAN}

Saran yang bisa peneliti sampaikan berdasarkan hasil peneilitian ini adalah: 1) penggunaan media seharusnya disesuaikan dengan situasi yang ada dikelas dan kemampuan mahasiswa yang ada. 2) untuk penelitian lanjutan sebaiknya mengembangkan bahan ajar, media, atau modul pembelajaran yang lebih baik, mudah digunakan dan dapat meningkatkan pembelajaran, baik hasil belajar, aktivitas mahasiswa, maupun mental mahasiswa, 3) penggunaan waktu yang lebih efisien dalam menerapkan suatu media untuk pembelajaran.

\section{DAFTAR RUJUKAN}

A. Sanwidi and G. T. Swastika. (2019). Direct learning models assisted by Lectora Inspire media to improve the understanding of geometry concepts. J. Phys. Conf. Ser., vol. 1188, p. 012061.

D. Sofnidar et al. (2013). Penerapan Pendekatan PMRI untuk Meningkatkan Kemampuan Konsep Geometri Mahasiswa PGSD Universitas Jambi. pp. 489-504.

J. A. Van de Walle. (2016). Elementary and Middle School Mathematics, Sixth edit. Virginia Commonwealth University.

Kemp, J. E. \& Dayton, D. K. (1985). Planning And Producing Instructional Media. New York: Harper and Row Publisher.

Kustandi, Cecep \& Bambang Suctipto. (2011). Media Pembelejaran Manual dan Digital. Bogor : Ghalia Indonesia.

Mas'ud, Muhammad. (2012). Membuat Multimedia Pembelajaran dengan Lectora, Yogyakarta: Shonif.

M. Pratiwi and T. Septia. (2016). Efektifitas Modul Aplikasi Komputer Dengan Program Wingeom pada Materi Geometri. LEMMA, vol. III, no. 1, pp. 97107. 
N. Ariani and D. Haryanto. (2010). Pembelajaran Multimedia di Sekolah Pedoman Pembelajaran Inspiratif, Konstruktif, dan Prospektif. Jakarta: Prestasi Pustaka.

Sugiyono. (2009). Metode Penelitian Kuantitatif Kualitatif dan RnD. Bandug: Alfabeta.

Sunardi, dkk. (2001). Konsep Dasar Penelitian Tindakan kelas. Makalah disajikan dalam Workshop Penelitian Tindakan Kelas (PTK). SLTP N 3 Jember, Jember, 23-25 Oktober 2001 